\title{
A novel urea biosensor based on zirconia
}

\author{
G. Sumana a , Maumita Das ${ }^{\mathrm{a}, \mathrm{b}}$, Saurabh Srivastava ${ }^{\mathrm{a}}$, B.D. Malhotra ${ }^{\mathrm{a}, *}$

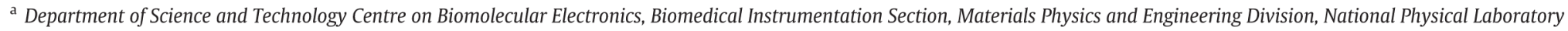 \\ (Council of Scientific and Industrial Research), Dr.K.S.Krishnan Marg, New Delhi 110012, India \\ ${ }^{\mathrm{b}}$ Department of Chemistry, University of Delhi, Delhi-110007, India
}

Keywords:

Biosensor

Urea

Nanostructured metal oxide

Zirconia

Electrochemical deposition

Glutamate dehydrogenase

Keto glutamate

Urease

\section{A B S T R A C T}

Electrochemically deposited biocompatible zirconia $\left(\mathrm{ZrO}_{2}\right)$ film on gold coated glass electrodes has been utilized for the fabrication of urea biosensor. The prepared $\mathrm{ZrO}_{2}$ films and bioelectrodes have been characterized using Fourier transform infrared (FT-IR) spectroscopy, scanning electron microscopy (SEM) and electrochemical techniques, respectively. The urea biosensor, fabricated by immobilizing mixed enzyme [urease (Urs) and glutamate dehydrogenase (GLDH)] on this nanobiomaterial, shows linearity up to $40 \mathrm{mg} \mathrm{dL}^{-1}$ of analyte (urea) and sensitivity of $0.071 \mu \mathrm{A} /\left(\mathrm{mM} \mathrm{cm}^{-2}\right)$ with stability up to 4 months when stored at $4{ }^{\circ} \mathrm{C}$. The low value of Michaelis-Menten constant $\left(K_{m}\right)$ estimated using Hans plot as $0.5 \mathrm{mM}$ indicates enhancement in the affinity and/ or activity of enzyme attached to this nanostructured biocompatible matrix.

\section{Introduction}

Estimation of urea in serum/blood/urine is important for the diagnosis of renal and liver diseases. An increase in urea level [normal range in blood is $8-20 \mathrm{mg} / \mathrm{dL}$ ] causes renal failure, urinary tract obstruction, dehydration, shock, burns, and gastrointestinal bleeding. Moreover, reduced urea level may cause hepatic failure, nephritic syndrome, and cachexia. Besides clinical diagnostics, urea estimation is an important parameter in pharmacy, food industry, environment monitoring and protection etc. In pharmaceutical industry, urea is used as a component of many ointments, its level in these products must be strictly controlled. In food industry, the control of food quality (mainly farm products) also includes determination of urea, for example in milk. The production of fertilizers and environmental protection are other areas for application of urea determinations. Urea levels in river or ground waters give the evidence of contamination with sewage. The high content of urea is one of the reasons for algae blooming [1-5].

Most urea biosensors (Urs), utilizing [Urs] are based on catalytic conversion of urea to hydrogen bicarbonate and ammonium. It has been observed that ammonium ions easily diffuse in solution. Thus, glutamate dehydrogenase (GLDH) has been used as an alternate since it catalyzes the reaction between ammonium ions, $\alpha$-ketoglutarate $(\alpha-K G)$ and nicotinamide adenine dinucleotide (NADH) to produce L-glutamate and $\mathrm{NAD}^{+}$.
The immobilization of Urs on a given matrix is a crucial step for the fabrication of urea biosensor. Extensive efforts have been made to utilize nanomaterials to immobilize Urs for urea detection. Nanostructured metal oxides such as cerium oxide, tin oxide and zirconia have been used for the fabrication of transducer surface because of their unique ability to promote faster electron transfer between electrode and active site of desired enzyme. Zirconia $\left(\mathrm{ZrO}_{2}\right)$ is an ideal material for immobilization of biomolecules with oxygen groups and it has significantly higher isoelectric point, $\mathrm{pH}$ stability and it plays an important role for optical, dielectric, corrosion-resistant coatings, and sensor applications [6-13]. Compared to sol gel method, electrodeposition of $\mathrm{ZrO}_{2}$ offers several advantages like strong adhesion between the deposited film that may be advantageous for biosensor fabrication [14,15]. Therefore, in the present manuscript, studies related to the fabrication of urea biosensor using electrochemically deposited biocompatible nanostructured $\mathrm{ZrO}_{2}$ film deposited onto $\mathrm{Au}$ surface have been reported.

\section{Experimental details}

\subsection{Materials}

Zirconium oxychloride $\left(\mathrm{ZrOCl}_{2} \cdot 8 \mathrm{H}_{2} \mathrm{O}\right)$, potassium chloride $(\mathrm{KCl})$, Urease (Urs), glutamate dehydrogenase (GLDH), nicotinamide adenine dinucleotide (NADH), $\alpha$-ketoglutarate $(\alpha-K G)$ have been procured from Sigma-Aldrich (USA). All chemicals used are of molecular biology grade. Deionized water (Milli Q $10 \mathrm{TS}$ ) has been used for the preparation of reagents. All the solutions and glassware are autoclaved prior to being used. 
2.2. Electrochemical deposition of nanostructured zirconium oxide film on gold coated glass plates $\left(\mathrm{ZrO}_{2} / \mathrm{Au}\right)$

Zirconia films have been deposited onto bare gold electrode in an aqueous electrolyte of $5.0 \mathrm{mmol} \mathrm{L}^{-1} \mathrm{ZrOCl}_{2}$ and $0.1 \mathrm{~mol} \mathrm{~L}^{-1} \mathrm{KCl}$ by cycling the potential between -1.5 and $+0.7 \mathrm{~V}$ (versus $\mathrm{Ag} / \mathrm{AgCl}$ ) at a scan rate of $20 \mathrm{mV} \mathrm{s}^{-1}$ for 10 consecutive scans [9]. This cathodic electrodeposition is based on the electro synthesis of inorganic $\mathrm{Zr}-\mathrm{O}^{-}$particles. In $\mathrm{ZrOCl}_{2} \cdot 8 \mathrm{H}_{2} \mathrm{O}$ solution, $\mathrm{ZrOCl}_{2}$ may hydrolyze to tetramer $\left[\mathrm{Zr}_{4}(\mathrm{OH})_{8}\left(\mathrm{H}_{2} \mathrm{O}\right) 16\right]^{8+}$ and form colloidal particles under the basic conditions around electrode surface that might have formed from the cathodic reduction of water as indicated in the following equation:

$2 \mathrm{H}_{2} \mathrm{O}+2 \mathrm{e}^{-} \rightarrow \mathrm{H}_{2}+2 \mathrm{OH}^{-}$

$\mathrm{Zr}-\mathrm{OH}+\mathrm{OH}^{-} \rightarrow \mathrm{Zr}-\mathrm{O}^{-}+\mathrm{H}_{2} \mathrm{O}$

Therefore, the negatively charged $\mathrm{Zr}-\mathrm{O}^{-}$colloidal particles are formed around the Au electrode. The electro synthesis helps in the accumulation of colloidal particles at the electrode surface resulting in the formation of the $\mathrm{ZrO}_{2}$ film.

\subsection{Immobilization of Urs and $\mathrm{GLDH}$ onto $\mathrm{ZrO}_{2} / \mathrm{Au}$ electrode}

$10 \mu \mathrm{L}$ of bienzyme solution containing Urs $(10 \mathrm{mg} / \mathrm{mL})$ and GLDH $(1 \mathrm{mg} / \mathrm{mL})$ in $1: 1$ ratio [prepared in Tris buffer $(5 \mathrm{mM})$ ] is immobilized onto $\mathrm{ZrO}_{2} / \mathrm{Au}$ electrode. The oxygen atom of the biomolecule covalently binds with the zirconium atom of zirconia, since both have the affinity to bind with each other. The Urs-GLDH/ $\mathrm{ZrO}_{2} / \mathrm{Au}$ bioelectrodes are kept undisturbed for about $12 \mathrm{~h}$ at $4{ }^{\circ} \mathrm{C}$. Finally, the dry bioelectrode is immersed in $50 \mathrm{mM}$ phosphate buffer saline (PBS) ( $\mathrm{pH} 7.0$ ) in order to wash out any unbound enzymes from the electrode surface.

\subsection{Characterization}

The morphological and structural characterization of the prepared electrodes have been carried out using Scanning electron microscopy (SEM, Leo 40) and Fourier transform infrared spectroscopy (FT-IR, Perkin-Elmer Model spectrum BX using ATR accessory), respectively. Electrochemical studies (cyclic voltammetry, differential pulse voltammetry and impedance measurements) have been carried out on Autolab Potentiostat/Galvanostat (Eco Chemie, Netherlands). These measurements are carried out using a three electrode cell with Urs$\mathrm{GLDH} / \mathrm{ZrO}_{2} / \mathrm{Au}$ bioelectrode as the working electrode, platinum (Pt) as the counter electrode, and saturated $\mathrm{Ag} / \mathrm{AgCl}$ electrode as a reference electrode in $50 \mathrm{mM}$ phosphate buffer saline of $\mathrm{pH} 7.0$ containing $5 \mathrm{mM}$ of $\left[\mathrm{Fe}(\mathrm{CN})_{6}^{-3 /-4}\right]$.

\section{Results and discussion}

\subsection{Optical properties}

Fourier transform infrared (FT-IR) spectra of $\mathrm{ZrO}_{2} / \mathrm{Au}$ electrode exhibits characteristic infrared absorption peaks (Fig. 1a) at $555 \mathrm{~cm}^{-1}$ and $668 \mathrm{~cm}^{-1}$ for the symmetric stretching of $\mathrm{Zr}-\mathrm{OZr}$ species indicating the formation of zirconia $\left(\mathrm{ZrO}_{2}\right)$ on the gold surface. The additional band observed at $1560 \mathrm{~cm}^{-1}$ and $1628 \mathrm{~cm}^{-1}$ are due to the vibration of $\mathrm{Zr}-\mathrm{O}-$ $\mathrm{C}$ species. In the FT-IR spectrum of Urs $-\mathrm{GLDH} / \mathrm{ZrO}_{2} / \mathrm{Au}$ bioelectrode (Fig. 1b), Urs-GLDH binding is indicated by the appearance of additional absorption bands at $1652 \mathrm{~cm}^{-1}$ assigned to the carbonyl stretch and also, a broad band seen around $3370 \mathrm{~cm}^{-1}$ is attributed to amide bond present in enzyme.

The results of SEM studies carried out on $\mathrm{ZrO}_{2} / \mathrm{Au}$ and Urs - GLDH/ $\mathrm{ZrO}_{2} / \mathrm{Au}$ electrodes are shown in Fig. 2. Uniform distribution of zirconium oxide nanoparticles with regular and patterned morphology is observed in the case of $\mathrm{ZrO}_{2} / \mathrm{Au}$ (image a). The presence of aggregated structure (image $b$ ) can be attributed to covalently bound Urs-GLDH molecules, indicating effective immobilization of enzyme.
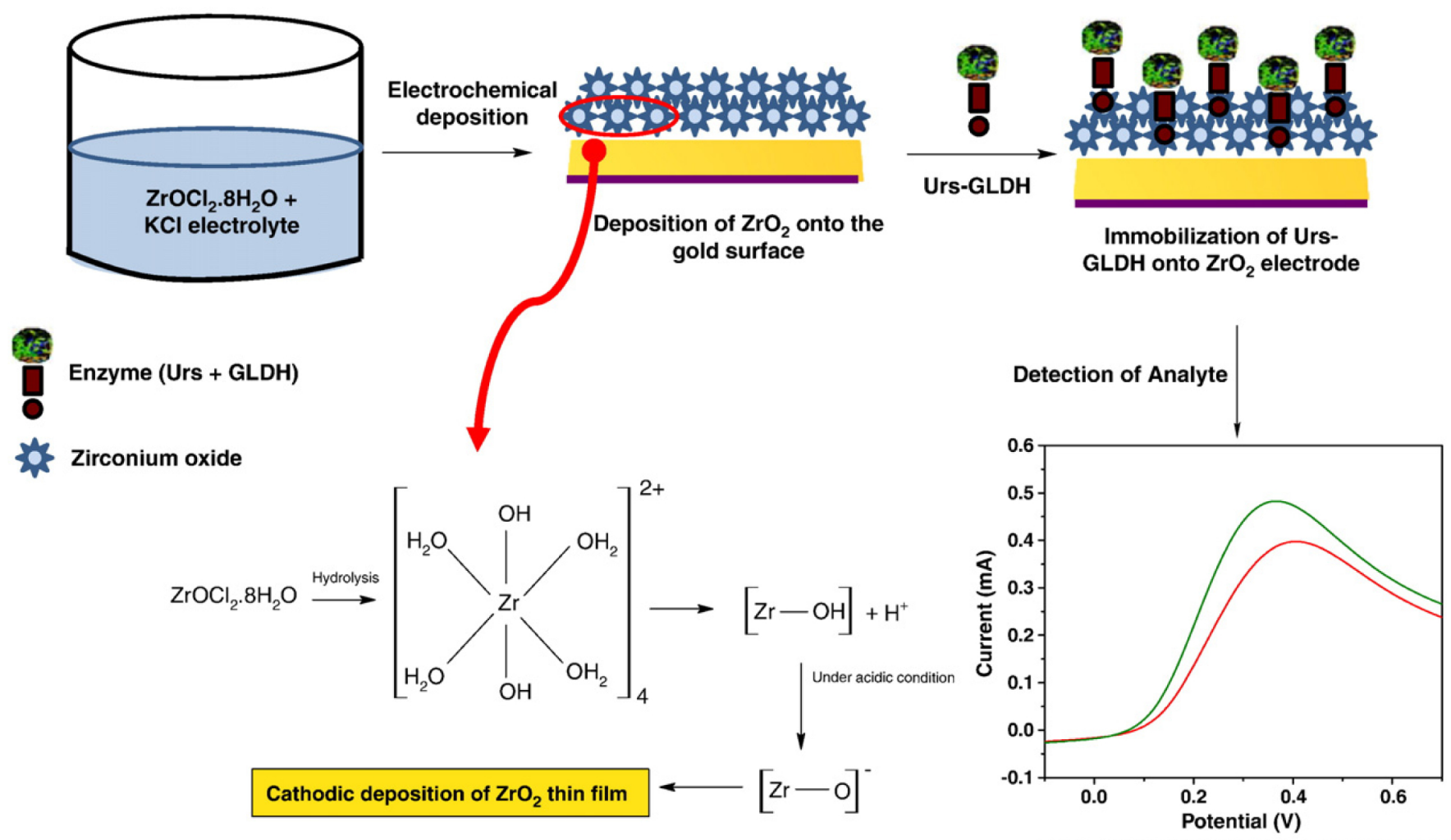

DPV curves for the detection of analyte 
A

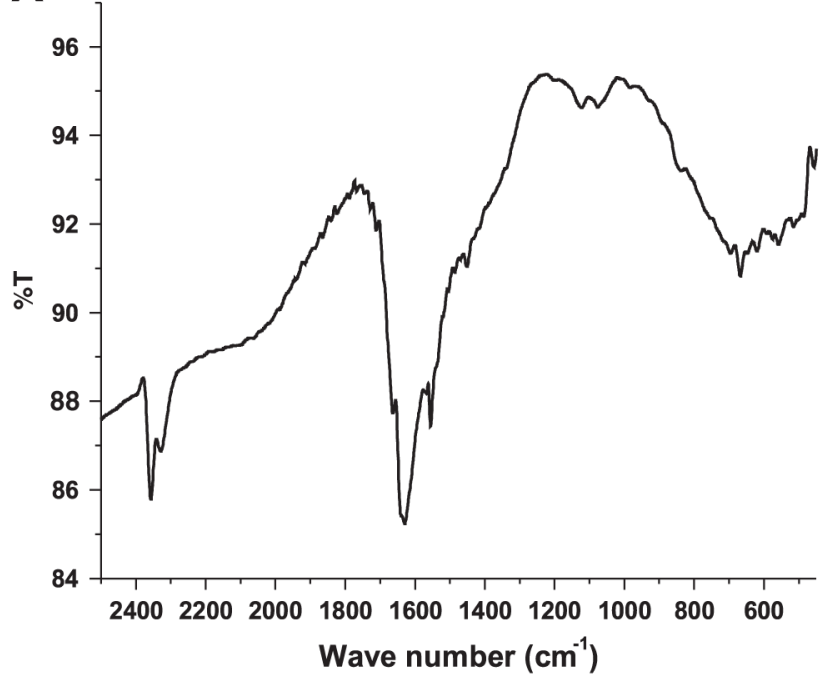

B

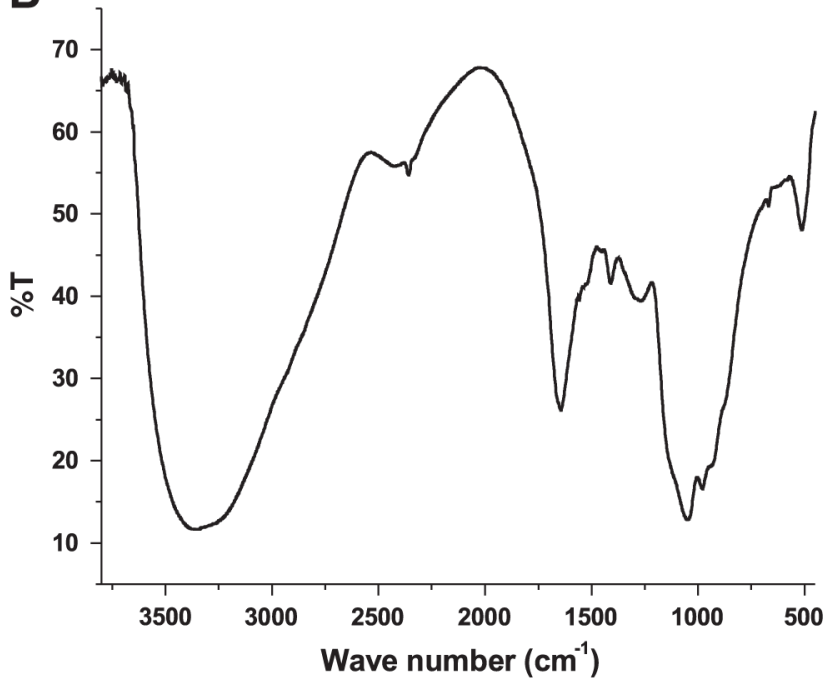

Fig. 1. FT-IR spectra of (A) $\mathrm{ZrO}_{2} / \mathrm{Au}$ and (B) Urs-GLDH/ZrO $/ \mathrm{Zu}_{2} / \mathrm{Au}$ electrodes.

\subsection{Electrochemical studies}

Cyclic voltammetric (CV) and electrochemical impedance spectroscopic (EIS) studies have been carried out in phosphate buffer saline (PBS, $50 \mathrm{mM}, \mathrm{pH}, 7.0,0.9 \% \mathrm{NaCl}$ ) containing $5 \mathrm{mM}\left[\mathrm{Fe}(\mathrm{CN})_{6}\right]^{3-/ 4-}$ and in the potential range, -0.6 to $0.6 \mathrm{~V}$ at $50 \mathrm{mV} / \mathrm{s}$ rate and in the frequency range, $0.01-105 \mathrm{~Hz}$, respectively with $\mathrm{ZrO}_{2} / \mathrm{Au}$ and Urs$\mathrm{GLDH} / \mathrm{ZrO}_{2} / \mathrm{Au}$ electrodes. In Fig. $3 \mathrm{~A}, \mathrm{ZrO}_{2} / \mathrm{Au}$ shows a well-defined redox behavior (curve a) at $0.288 \mathrm{~V}\left(\mathrm{E}_{\mathrm{pc}}\right.$ ) and the cathodic peak current at $5.45 \times 10^{-4} \mathrm{~A}$. But the redox peak current decreases to $2.35 \times 10^{-4} \mathrm{~A}$ after immobilization of Urs-GLDH (curve b). This may be due to the insulating nature of Urs-GLDH enzyme that may perturb the electron transfer between the medium and the electrode resulting in the slowing down of redox process during the biochemical reaction. In EIS (Fig. 3B), the semicircle part corresponds to electron transfer limited process and its diameter is equal to the electron transfer resistance, $R_{C T}$ that controls electron transfer kinetics of the redox probe at the electrode interface. It can be seen that the value of $\mathrm{R}_{\mathrm{CT}}$ obtained as $183 \Omega$ for $\mathrm{ZrO}_{2} /$ Au electrode (curve a) increases to $890 \Omega$ for Urs-GLDH/ZrO $/$ /Au bioelectrodes (curve b). This increase in $R_{C T}$ is attributed to the fact that most biological molecules, including enzymes, are poor electrical conductors at low frequencies (at least $<10 \mathrm{kHz}$ ) and cause hindrance to the electron transfer. These results indicate binding of Urs-GLDH onto $\mathrm{ZrO}_{2} / \mathrm{Au}$ electrode.
Fig. $3 \mathrm{C}$ shows $\mathrm{CVs}$ of Urs-GLDH/ZrO $/ 2$ Au bioelectrodes as a function of scan rate from 50 to $300 \mathrm{mV} / \mathrm{s}$. The proportional increase of redox current with respect to scan rate is observed indicating diffusioncontrolled system. The surface concentration of Urs-GLDH/ZrO $\mathrm{Zr}_{2} / \mathrm{Au}$ bioelectrode estimated from plot of $i_{p}$ versus scan rate, using BrownAnson model has been found to be $2.34 \times 10^{-7} \mathrm{~mol} \mathrm{~m}^{-2}$. The diffusion coefficient has been estimated using Sandel-Sevcik equation.

$I_{p}=\left(2.69 \times 10^{5}\right) n^{3 / 2} A D^{1 / 2} C v^{1 / 2}$

where $I_{\mathrm{p}}$ is peak current, $\mathrm{n}$ is electron stoichiometry, $A$ is electrode area $\left(0.05 \mathrm{~m}^{2}\right), C$ is surface concentration $\left(2.34 \times 10^{-7} \mathrm{~mol} \mathrm{~m}^{-2}\right)$, and $\nu$ is scan rate $(50 \mathrm{~V} / \mathrm{s})$. The $D$ value has been obtained as $8.32 \times 10^{-5} \mathrm{~m}^{2} \mathrm{~s}^{-1}$.

\section{Electrochemical response studies}

Electrochemical response studies of Urs-GLDH/ $/ \mathrm{ZrO}_{2} / \mathrm{Au}$ bioelectrode have been carried out as a function of urea concentration in the presence of $30 \mu \mathrm{L}$ of nicotinamide adenine dinucleotide (NADH, $3.7 \mathrm{mg} / \mathrm{dL}$ ) and $70 \mu \mathrm{L}$ of $\alpha$-Keto glutarate $(\alpha-K G, 47.5 \mathrm{mg} / \mathrm{dL})$ using differential pulse voltammetry in PBS solution $\{50$ mMPBS ( $\mathrm{pH} 7,0.9 \%$ $\mathrm{NaCl}$ ) containing $\left.5 \mathrm{mM}\left[\mathrm{Fe}(\mathrm{CN})_{6}\right]^{3-/ 4-}\right\}$. It is observed that the magnitude of current obtained for the Urs-GLDH/ZrO $/ \mathrm{Au}$ bioelectrode increases on addition of urea (Fig. 4A). The response time of the

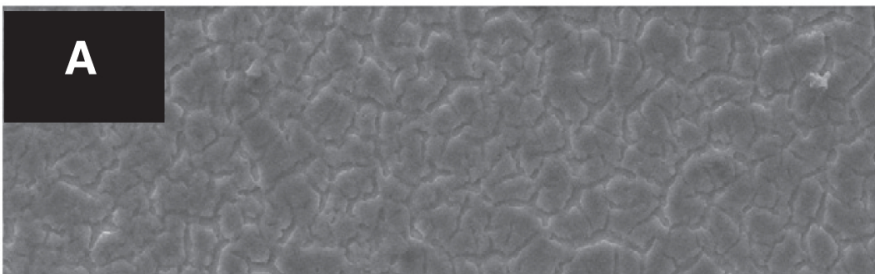

\section{Mag $=2.0 \mathrm{KX} ; 10 \mu \mathrm{m}$}

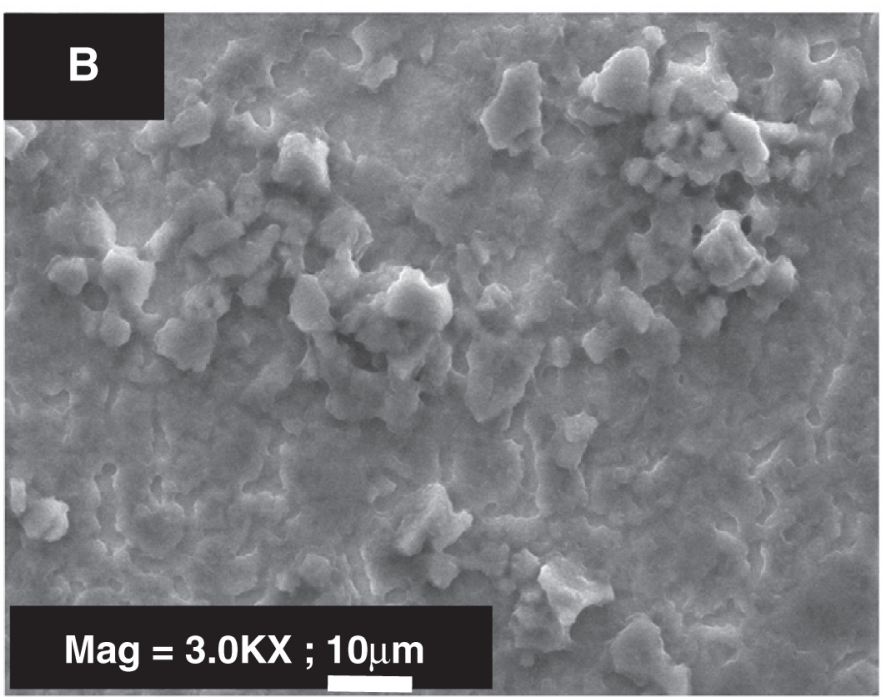

Fig. 2. SEM images of (A) $\mathrm{ZrO}_{2} / \mathrm{Au}$ and (B) Urs-GLDH/ $\mathrm{ZrO}_{2} /$ Au electrodes. 
A

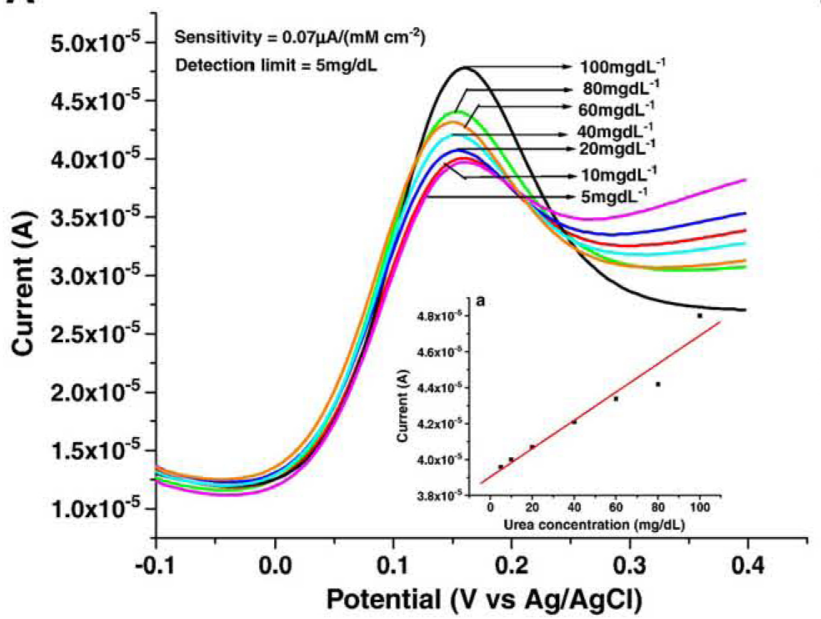

B

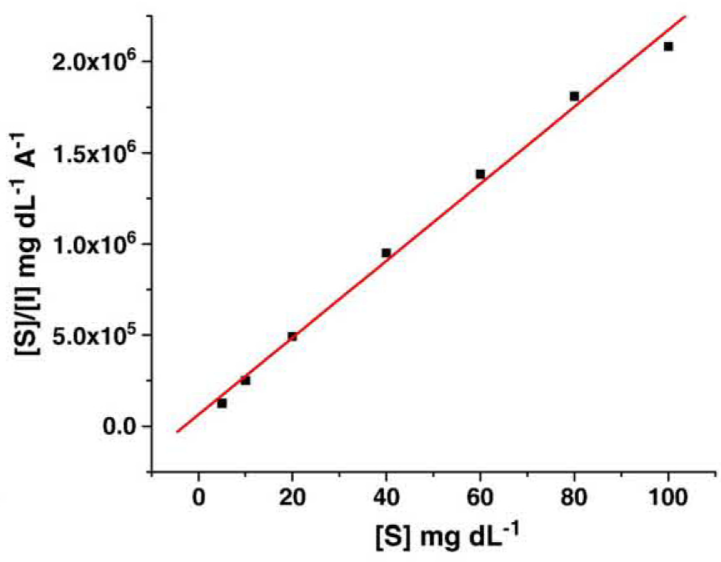

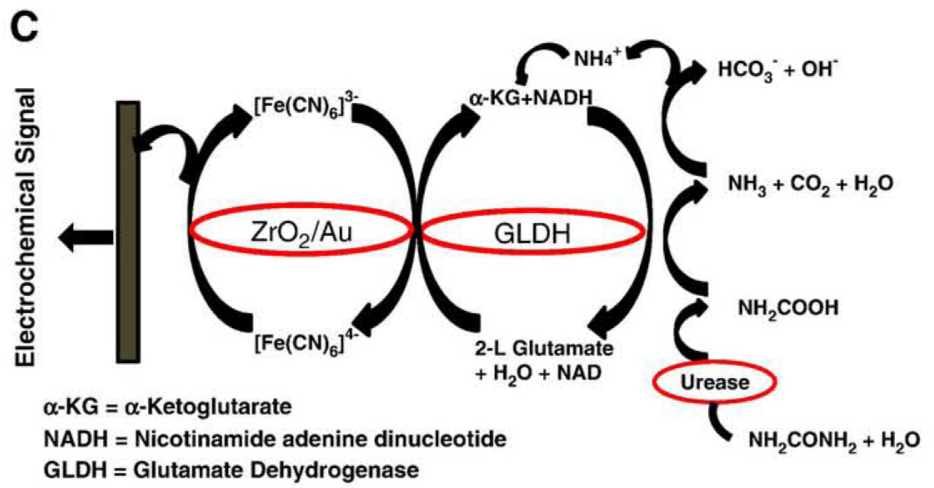

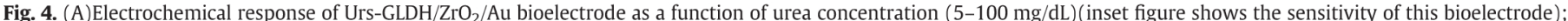
(B) Hans plot for $K_{m}$ values; (C) Biochemical reaction during electrochemical detection of urea using Urs-GLDH/ZrO $/ \mathrm{Zu}_{2} / \mathrm{Au}$ bioelectrode.

\section{References}

[1] F. Kuralay, H. Özyörük, A. Yýldýz, Sens. Actu. B 114 (2006) 500-506.

[2] B. Lakard, G. Herlem, S. Lakard, A. Antoniou, B. Fahys, Biosens. Bioelectron. 19 (2004) 1641-1647.

[3] A. Sehitogullari, A.H. Uslan, Talanta 57 (2002) 1039-1044.

[4] M. Guti'errez, S. Alegret, M.D. Valle, Biosens. Bioelectron. 22 (2007) 2171-2178.

[5] S. Karakus, ule Pekyardýmcý, and Esma Kýlýc, Artif. Cells, Blood Substit. Biotechnol. 33 (2005) 329-341.

[6] G. Sumana, M.K. Pandey, B.D. Malhotra, J. Mater. Res. 24 (2009) 1667-1673.

[7] Pratima Solanki, Ajeet Kaushik, Anees A. Ansari, G. Sumana, B.D. Malhotra, Appl. Phys. Lett. 93 (2008) 163903.

[8] Gunjan Dhawan, G. Sumana, B.D. Malhotra, Biochem. Eng. J. 44 (2009) 42-52.

[9] M. Fang, D.M. Kaschak, A.C. Sutorik, T.E. Mallouk, J. Am. Chem. Soc. 119 (1997) 12184-12191.

[10] Qinyuan Zhang, Xiaoli Li, Jun Shen, Wu. Guangming, Jue Wang, Lingyan Chen, Mater. Lett. 45 (2000) 311-314.
[11] Shou-Qing Liu, Jing-Juan Xu, Hong-Yuan Chen, Bioelectrochemistry 57 (2002) 149-154.

[12] Yunhui Yang, Zhijie Wang, Minghui Yang, Jishan Li, Fang Zheng, Guoli Shen, Ruqin Yu, Anal. Chim. Acta 584 (2007) 268-274.

[13] C.T. Buscher, D. McBranch, D.Q. Li, J. Am. Chem. Soc. 118 (1996) 2950-2953.

[14] Maumita Das, Gajjala Sumana, R. Nagarajan, B.D. Malhotra, Appl. Phys. Lett. 96 (2010) 133703.

[15] N.N. Zhu, A.P. Zhang, Q.J. Wang, P.A. He, Y.Z. Fang, Anaytica Chimica Acta 510 (2004) 163-168.

[16] A. Kumar, Rajesh, A. Chaubey, S.K. Grover, B.D. Malhotra, Journal of Applied Polymer Science 82 (2001) 3486-3491.

[17] S.K. Arya, P.R. Solanki, Ravindra P. Singh, M.K. Pandey, M. Datta, B.D. Malhotra, Talanta 69 (2006) 918-926.

[18] Ajeet Kaushik, Raju Khan, Pratima Solanki, Pratibha Pandey, Javed, Sharif Ahmad, B.D. Malhotra, Biosensors \& Bioelectronics 24 (2008) 676-683.

[19] M. Gerard, K. Ramanathan, A. Chaubey, B.D. Malhotra, Electroanalysis 11 (1999) 45 . 